\title{
The role of the pathology department in the preanalytical phase of molecular analyses
}

This article was published in the following Dove Press journal:

Cancer Management and Research

\author{
Sergiu Susman ${ }^{1,2}$ \\ loana Berindan-Neagoe ${ }^{3}$ \\ Bobe Petrushev ${ }^{3}$ \\ Radu Pirlog 2 \\ loan-Stefan Florian ${ }^{4}$ \\ Carmen-Mihaela Mihu ${ }^{2}$ \\ Cristian Berce ${ }^{3}$ \\ Lucian Craciun ${ }^{2}$ \\ Ravnit Grewal ${ }^{5}$ \\ Ciprian Tomuleasa ${ }^{3,6,7}$ \\ 'Department of Pathology, Imogen \\ Research Center, ${ }^{2}$ Department of \\ Morphological Sciences, ${ }^{3}$ Research \\ Center for Functional Genomics and \\ Translational Medicine, ${ }^{4}$ Department \\ of Neurosurgery, luliu Hatieganu \\ University of Medicine and Pharmacy, \\ ${ }^{5}$ Department of Hematology, Ion \\ Chiricuta Oncology Institute, \\ ${ }^{6}$ Department of Hematology, luliu \\ Hatieganu University of Medicine \\ and Pharmacy, Cluj-Napoca, Romania; \\ ${ }^{7}$ Department of Haematopathology, \\ Tygerberg Academic Hospital, \\ Tygerberg, South Africa
}

Correspondence: Ciprian Tomuleasa Research Center for Functional Genomics and Translational Medicine, luliu Hatieganu University of Medicine and Pharmacy, 23rd Gheorghe Marinescu Street, Cluj-Napoca, 400000, Romania $\mathrm{Tel}+4074$ I 337480

Email ciprian.tomuleasa@umfcluj.ro

\begin{abstract}
After introducing the new molecules for the treatment of patients with tumoral pathology, the therapeutical decision will be taken depending on the molecular profile performed upon the harvested tissues. This major modification makes the molecular and morphological analysis an essential part in the clinical management of patients and the pathologist plays an important role in this process. The quality and reproducibility of the results are imperative today and they depend on both the reliability of the molecular techniques and the quality of the tissue we use in the process. Also, the genomics and proteomics techniques, used increasingly often, require high-quality tissues, and pathology laboratories play a very significant role in the management of all phases of this process. In this paper the parameters which must be followed in order to obtain optimal results within the techniques which analyze nucleic acids and proteins were reviewed.
\end{abstract}

Keywords: nucleic acids, proteins, fixation, freezing, molecular techniques

\section{Introduction}

The recent progress made in the detection of molecular events with a key role in the development of tumors, as well as the advent of new drugs capable of blocking molecular targets, has led to the mandatory increase in standardization and quality control for the molecular biology techniques employed. The same applies to the tissue-processing stages that precede these assays. ${ }^{1-3}$ Nowadays, the detection of mutated or amplified genes such as $H E R 2, K R A S, B R A F$, and C-KIT makes personalized treatment possible, and in addition, the evaluation of estrogen $(\mathrm{E})$ and progesterone $(\mathrm{P})$ expression, for example, has led to the improvement of the clinical condition of patients. ${ }^{47}$ Furthermore, the genomics and proteomics techniques that are increasingly being used often require high-quality tissues; therefore, the pathology laboratories play a very significant role in the management of all phases of this process. ${ }^{8}$ In recent years, efforts made precisely in this regard have remarkably improved the techniques, the reagents, and the equipment in terms of standardization and quality control methods. Consequently, the errors that occurred during the analytical phase have been reduced by $\sim 10$ times. Therefore, it could be argued that these methods have reached an acceptable level of reliability. ${ }^{9}$ In addition, attention is now being paid to the preanalytical phase, as it was somewhat overlooked in the past; however, it is becoming more important with the advent of molecular diagnostics and targeted therapies. ${ }^{10}$

The preanalytical phase includes all procedures performed upon a tissue fragment, from harvesting to the molecular analysis. The main departments involved in this process are surgery and especially pathology. ${ }^{11}$ The reception of tissues, their 
fixation, freezing or embedding in paraffin, the diagnostic, and the evaluation of tissue quality are all essential stages of the preanalytical phase and are the exclusive domains of the pathologist. ${ }^{12}$ The archives of the pathology departments are, at present, an important source of tissues where molecular biology techniques can be applied in order to identify new markers, which link to the evolution of patients and their response to the treatment. Both classic techniques, such as immunohistochemistry (IHC), and the recent ones need the standardization of the preanalytical stages. In this paper we focused on parameters which can be followed in order to obtain high-quality tissues for molecular testing and also the limitations of applying the new techniques on formalin-fixed paraffin-embedded tissues (FFPE) (Figure 1).

\section{Protein evaluation}

At present, a series of molecular biomarkers are used in the clinical management of patients, and they need to be precisely assessed. This is why each pathology laboratory that assesses these biomarkers must provide accurate and reproducible results. This requires a standardization of the methods employed in tissue processing. ${ }^{13}$

\section{IHC}

Generally, fixation must be made within a timeframe of up to 12 hours. During this period, the storage of tissues at $4^{\circ} \mathrm{C}$ or at room temperature does not influence the quality of the immunomarking. The effects seen after $>12$ hours seem to be antigen specific. ${ }^{14-16}$

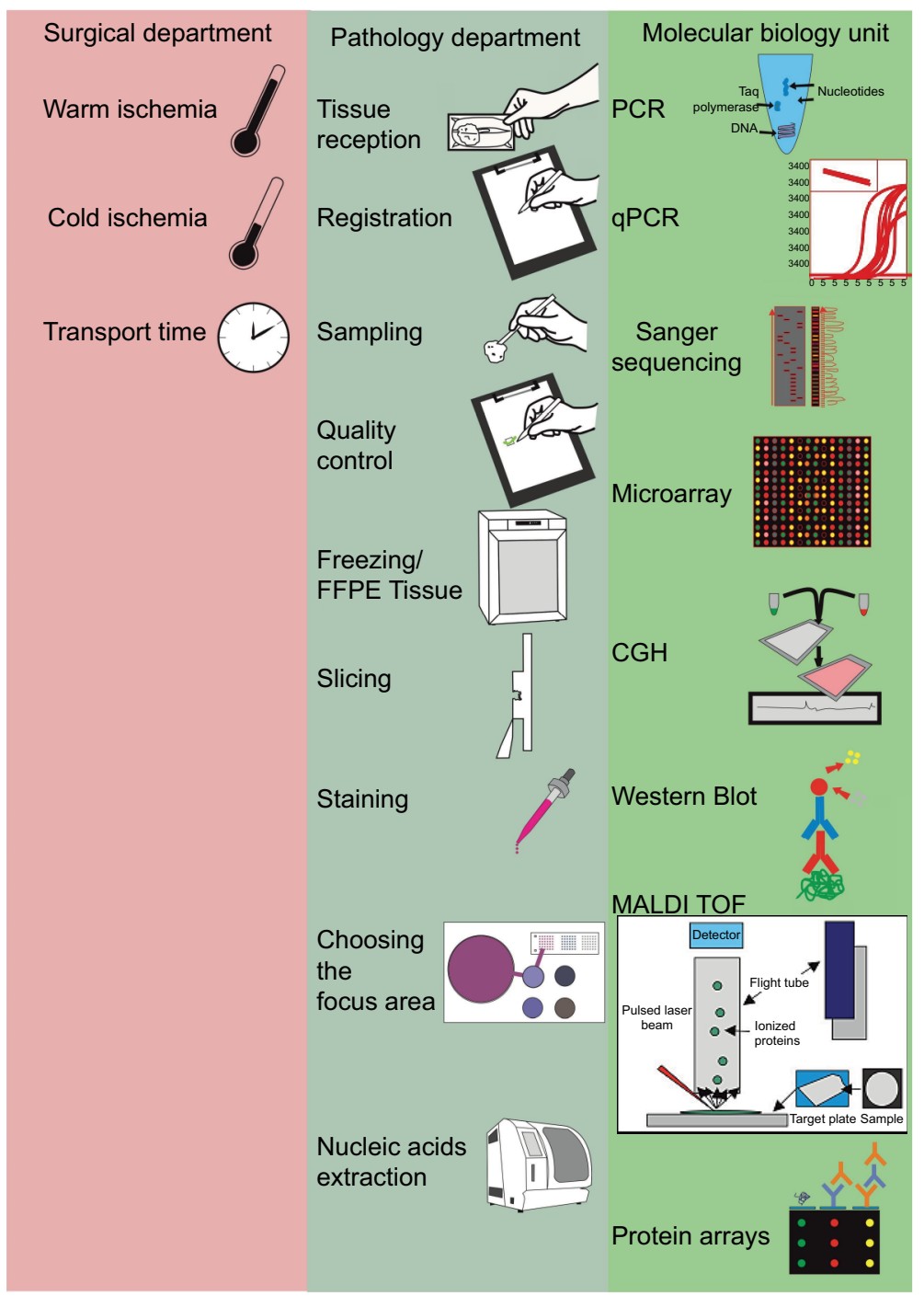

Figure I Overview of the general responsibilities of surgical, pathology, and molecular medicine departments in the tissue analysis flow.

Note: The pathology departments are at the core of tissue analysis, thus ensuring the quality control for tissue processing in all of the departments involved in biomedical research and in state-of-the-art molecular analyses.

Abbreviations: CGH, chorionic gonadotrophin; FFPE, formalin-fixed paraffin-embedded; MALDI TOF, mass spectrometry; PCR, polymerase chain reaction; qPCR, quantitative PCR. 
The fixative solution on the other hand is influenced by the concentration, the $\mathrm{pH}$, and the presence of the buffer as these factors contribute toward optimal immunomarking. The best formula is the $10 \%$ neutral-buffered formalin (NBF) with a $\mathrm{pH}$ between 5 and 7, although it may differ from one antigen to another. The ratio between the volume of the tissue and that of the fixative solution may vary considerably. It is generally accepted that the optimum ratio for a good fixation is $1: 10$; however, the ratio has been reported to vary from 1:10 to $1: 20{ }^{17}$

Differences may also occur between various areas of the tissue sample, such as between the periphery and center of a sample as this affects the intensity and the number of positive cells. The penetration of tissues takes place at different speeds, depending on its depth; in order to double the depth, the time must be increased by four times. ${ }^{18}$ Of note is the fact that formalin ensures the fast penetration of tissues but remains slow in terms of fixation. For a better quality of the tissues used for immunochemistry purposes, fixation is more important than penetration time. Experiments performed on mouse liver showed a plateau after $\sim 24$ hours. The temperature at which fixation takes place is also very important, as it is faster at $37^{\circ} \mathrm{C}$ than at $25^{\circ} \mathrm{C}$. The $\mathrm{pH}$ also influences fixation time, which is shorter at 7.0 than at 4.0. The rinsing of tissues fixed for a long period of time shows that fixation is a reversible process. ${ }^{19}$

The extended ischemia due to late fixation may decrease the expression of estrogen receptor (ER) and progesterone receptor $(\mathrm{PR})$ in breast cancer. The ER expression begins to drop 2 hours after sampling, and the PR expression drops after 1 hour. After 8 hours, the expression becomes completely negative. Therefore, fixation should be made within a maximum of 1 hour. ${ }^{20} \mathrm{~A}$ minimum fixation time of 6-8 hours is required for the optimal expression of receptors, while the maximum fixation time that may be reached without a change in the ER, PR, or HER2 expression is 72 hours. ${ }^{21-23}$

In order to show the importance of standardizing the immunohistochemical expression of ER and PR in breast cancer, a Guideline Recommendation was published at the initiative of the American Society of Clinical Oncology and the College of American Pathologists. In these guidelines, it was noted that $\sim 20 \%$ of the IHC determinations are inaccurate, mostly due to a "variation in preanalytic variables". According to these guidelines, the requirement for optimal tissue handling is that the time between the reception of the tissue and fixation should be as short as possible. The tissue fragments must be cut into slices that are $\sim 5 \mathrm{~mm}$ thick, fixed only in $10 \% \mathrm{NBF}$, in quantities suitable for a good penetration of the tissue (10-fold greater than the volume of the specimen). A higher or lower concentration of NBF will not be accepted. ${ }^{24}$ The fixation time should be between 6 and 72 hours. Also, the cold ischemia time, the type of fixator, and the fixating time should be recorded. Each fragment should be accompanied by a sheet indicating the warm and cold ischemia times (the surgeon's duty) and also the fixation time, the type of fixator, and the fixation duration (the pathologist's duty). The time between tumor harvesting and fixation should be kept at $<1$ hour. The pathologist must keep track of these parameters and notify them to the team performing the study.

With respect to the expression of HER-2, slides must be stored for no more than 6 weeks prior to the evaluation. Just like in the case of the receptors, the time until fixation should be as short as possible. The fixation time should be longer than 6 hours; however, it should not exceed 48 hours. Fixation should be made in a sufficient volume of $10 \% \mathrm{NBF}^{25}$

In proteomics, certain signal transduction pathway phosphoproteins, known sensitive indicators of tissue state, may suffer changes in expression levels that mask the levels at the time of excision, depending on tissue handling and cold ischemia delay. Due to factors such as postexcision hypoxia and stress-response signals, certain kinase proteins may suffer expression level alterations during the cold ischemia delay. As a solution to this unwanted variance, Espina et $\mathrm{al}^{26}$ have developed guidelines based on studies regarding postexcision phosphoprotein expression fluctuations in different organs. To further compensate for rapid enzyme function alteration, procedures such as thermal or pressure inactivation of enzymes involved in cell signaling (protein kinases, phosphatases, or even RNAses) have been developed. ${ }^{27}$ However, such methods lead to the loss of tissue morphology preservation. In any case, protein phosphorylation changes significantly after 10-15 minutes of cold ischemia. For example, it has been noted that phosphorylated $m T O R$ levels greatly increase after 45 minutes. ${ }^{28}$ Based on a range of evidence, the TuBaFrost consortium has suggested a maximum time of 30 minutes to flash-freezing, based on mass spectrometry-based evidence. ${ }^{29}$ As general recommendations for the reduction of preanalytical variability, Espina et $\mathrm{al}^{26}$ indicate that elapsed time between tissue extraction and stabilization should not reach 20 minutes and that additional variables, such as sample excision and collection time, elapsed time to preservation or stabilization, and length of fixation time, should be recorded to provide a measure of sample quality. Additional proteome integrity assays should be performed, and these include Western blot (WB) for the evaluation of marker protein proteolysis, effects of preservation, and posttranslational 
modifications; evaluation of proteolysis of abundant proteins over time by 2-dimensional (2D)-gel electrophoresis (GE), and evaluation of tissue morphology and immunoreactivity through microscopic evaluation. ${ }^{30}$

After samples have been received in the pathology laboratory, tissues may undergo formalin fixation, which leads to protein-protein cross-linking and requires digestion with proteinases. This may affect protein assay results, as shown in studies comparing some commonly used preservation methods, including formalin fixation. A first study noticed that, in contrast to fresh frozen samples, FFPE tissues failed to yield identifiable target proteins through 2D GE, and another team subsequently reported similar results through the use of chromatographic methods, ${ }^{31,32}$ supposedly because of the protein mesh that forms after protein cross-linking. These difficulties were later resolved by the use of new protocols. ${ }^{33}$ However, other studies reported minimal modification of proteins after formalin fixation. ${ }^{34}$ To circumvent possible formalin-induced protein modifications, some studies have suggested the use of alternative fixatives, such as FineFix, RCL2, and HOPE. ${ }^{35,36}$

In order to optimize protein extraction from FFPE tissues, Shi et al have used a method widely applied in IHC. FFPE were boiled in an antigen retrieval solution of Tris-HCL ( $2 \%$ sodium dodecyl sulfate [SDS]), followed by incubation. Fresh tissue from the same sample was processed to compare the efficiency of protein extraction. Evaluation of the extraction quality done by GE and mass spectrometry showed better results for high temperature-heated FFPE tissues. ${ }^{33}$

In the process of tissue protein separation for gel-based assays, enzymatic digestion and application of increased detergent concentrations such as SDS can produce peptides, which can be further modified by tissue formalin increasing the risk of interference with mass spectrometric analysis methods. ${ }^{37,38}$ Protein extraction methods may use different homogenization techniques, which may damage proteins by exposure to tissue proteases that can cause protein degradation, especially in frozen tissues. Consequently, some studies recommend the use of quick, low-temperature protein extraction methods and the use of protease enzymatic inhibitors. ${ }^{39}$ To avoid the risk of protease-mediated protein degradation altogether, other more integrated proteomic-inclined approaches may employ heat, instead of freezing stabilization methods, as they have been shown to have superior results when compared to a combination of flash-freezing and enzymatic inhibitors. ${ }^{40}$ Protein extraction yield as well as quality measured by WB assays has also been shown to be enhanced through the use of an established (EBX) and commercial buffer (EBX Plus) when used on a variety of cancerous and noncancerous tissues that have undergone formalin fixation even for extended periods of time (144 hours). ${ }^{41}$

Recently, FFPE tissues have been regarded as a possible source of material for WB assays. Results from a study on renal cancer showed that, compared to frozen tissue extracts, FFPE tissues lead to similar results through WB, although membrane protein expression was reported to have a greater variability. ${ }^{42}$ In addition, RP protein array analysis showed similar results in the level of intact protein extraction rate, with a greater sensitivity attributed to the RP protein array method, in contrast to WB assays (Figure 2). ${ }^{43}$

\section{Nucleic acids}

The various procedures that tissues undergo either in surgery or in the pathology laboratory have different effects in terms of biomolecule stability. Among the most sensitive of molecules, RNA expression may vary even with little exposure to the environment. For instance, warm ischemia has been

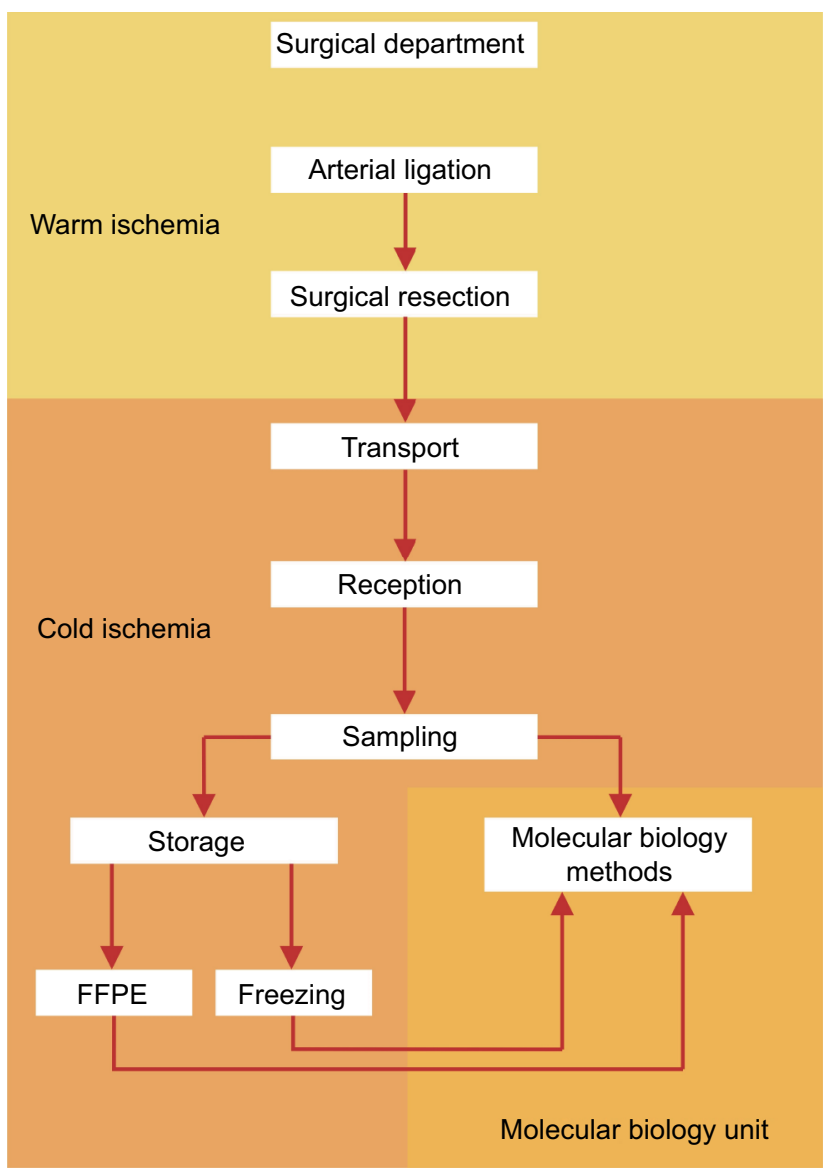

Figure $\mathbf{2}$ The steps of the preanalytical phase and their matching with the times of warm/cold ischemia.

Note: Most steps are possible during cold ischemia, thus reducing as much as possible processing time and ensuring a good tissue quality for molecular testing. Abbreviation: FFPE, formalin-fixed paraffin-embedded. 
proven to affect RNA quality and level detection, the degradation of which may be lowered through tissue cooling. ${ }^{44} \mathrm{On}$ the other hand, some studies have shown that cold ischemia duration decreases RNA integrity levels only to a modest degree, affecting both RNA integrity number and yielded quantity levels, ${ }^{45,46}$ while in other studies such effects of cold ischemia were not observed. ${ }^{47,48}$ The American Society of Clinical Oncology and College of American Pathologists have produced guidelines regarding the cold ischemia interval, which should remain below 2 hours. ${ }^{25}$ Others propose a gold standard of 30 minutes, although some evidence exists that even with such a small delay, effects on tissues such as gene expression may be significant. ${ }^{49,50}$ Concurrent measurement of the reduction of housekeeping gene expression levels may provide information regarding the levels of RNA quality degradation. ${ }^{51}$ The fixation process has great influence on RNA quality because it causes strand breakage and crosslinking with other biomolecules. RNA from FFPE samples was found to be heavily degraded and fragmented so that only short sequences, $~ 100-200$ nucleotides long, could be recognized and amplified through polymerase chain reaction (PCR). ${ }^{52,15}$ Small tissue fragments and short fixation times -8 hours in formalin - should provide the best nucleic acid conservation and best tissue morphology preservation..$^{53}$ The quality of these parameters may also be preserved through a variant of the formaldehyde fixation process, which lowers the process temperature at $4^{\circ} \mathrm{C} .{ }^{54}$ As the level of RNA integrity conservation in FFPE specimens is low, alternative solutions, such as RNAlater tissue freezing, may be employed with significant results. Frozen tissues are known to provide a greater quantity of high-quality RNA and DNA than FFPE tissues for assays involving nucleic acids. ${ }^{55,45}$ By causing precipitation of tissue RNA-ses, it has been shown that RNAlater increases both RNA integrity number values and also can cause a threefold increase in RNA-yielded quantity results that are similar to or even greater than those obtained through the flash freeze technique. ${ }^{56}$ Other studies, however, suggest that freezing still may be preferred over RNAlater. Consequently, The Tumor Analysis Best Practices Group, a group of investigators employing a commercial microarray platform widely used in clinical trials, has the following recommendations: all tissue samples should be flash frozen within minutes of surgery and stored at $\leq-80^{\circ} \mathrm{C}$. Samples should also be kept in small, airtight containers and kept from drying out during frozen storage by placing fragments of ice in with the sample. ${ }^{57}$

In addition to mRNA, the recently discovered microRNA is a potential biomarker for many diseases that impose surgical treatment. ${ }^{58}$ Unlike the former, however, microRNA seems to have greater postexcision stability than mRNA, possibly because of its stable association with proteins in the Argonaute 2 complex. ${ }^{59}$ Many studies have shown that expression profiles of microRNAs generally remain comparable to those derived from frozen tissues, independently of the use of widely used fixatives or storage time or even the employed microRNA profile assay method ${ }^{60}$ Also, microRNA expression might not be influenced by the use of methods such as formalin fixation methods or immunocytochemical methods. ${ }^{61}$ Finally, studies that assess the effect of warm or cold ischemia time intervals on microRNA profiles are still missing.

As we have mentioned, nucleic acids are more susceptible to degradation through the use of fixation techniques. Consequently, fresh-frozen tissue specimens are the preferred source for nucleic acid-based assays. However, because of the limited availability of such tissues, attention has been given to FFPE tissues as an alternative source of genetic material. After surgery, it is known that a longer prefixation time interval may cause DNA integrity level change..$^{62} \mathrm{~A}$ possible solution is the use of commercial formulations capable of denaturing nucleases, such as the Whatman FTA paper, which even allows the storage of tissues at room temperature while preventing DNA damage and increasing DNA assay results after tissue processing shown to be excellent sources of DNA; FFPE tissues create additional problems in terms of material extraction and analysis. ${ }^{63-65}$ In addition, it has been observed that DNA isolated from FFPE tissue contains more PCR inhibitors than DNA isolated from nonfixed specimens. ${ }^{66}$ However, new studies that compare modern DNA isolation methods may provide recommendations for the selection of protocols that yield optimal results with nucleic acid assays such as PCR.${ }^{67}$ Other nucleic assays may be deemed impractical on FFPE tissues. Some sequencing studies have shown through sequencing methods that as much as one artificial mutation per 500 bases may result from the formalin fixation process ${ }^{68}$ However, next-generation sequencing (NGS) has yielded excellent results even with single-nucleotide variant calls or interpretation of insertions and deletions, which are some of the issues arising when analyzing FFPE tissues. ${ }^{69}$ Furthermore, a new study evaluating the lung cancer $K R A S$, $B R A F$, and EGFR gene mutations has compared both the NGS and real time-PCR assays and proved that while the results obtained by both methods were similar, NGS was able to detect both single-nucleotide and insertion-deletion variations. In addition, a new study by Wagle et al ${ }^{70}$ provides a method combining hybridization-capture and deep 
sequencing, which maximize sequence yield and lower overall assay costs. Regarding a-chorionic gonadotrophin, early studies suggested that DNA samples obtained from FFPE tissues were uninterpretable because of various errors such as oversaturation and nonuniformity in replicates. ${ }^{71}$ Recent advances have surmounted these impediments and even compared these new methods to suggest optimal a-chorionic gonadotrophin platforms. ${ }^{72}$

If both the warm and hot ischemia times are optimal, fixation using paraformaldehyde does not produce any alterations of the nucleic acids. Considering that formaldehyde acts mainly on the protein level by forming - $\mathrm{CH} 3$ chemical connections, it has a lower effect on the quality and preservation of both DNA and RNA. Fragmentation of the nucleic acids is mainly found in paraffin-embedded tissues. Still, new assays for molecular analysis such as next-generation sequencing or methylation arrays are associated with limited fragmentation of the nucleic acids and the results of the analysis are not influenced by the degree of alteration in paraffin-embedded tissues. Thus, even if the experience of various pathology laboratories is limited in this regard, molecular analyses should use paraffin-embedded tissues that are not older than 10 years, as according to the guidelines. ${ }^{73-75}$

In the case of protein decalcification, the process may influence molecular testing, considering that one of the most common types of biopsies that are decalcified are the bone marrow biopsies. Thus, the International Council for Standardization in Hematology (ICSH) has set up guidelines that aim to bring together the various protocols for tissue decalcification and still maintain an optimum quality of the biopsy material for the IHC staining. ${ }^{76}$ The best protocol of decalcification for IHC staining is ethylenediaminetetraacetic acid based, lasting between 16 and 24 hours, and the strong acids used have allowed the keeping of the various differentiation markers on the cell surface. Decalcification should be followed by a careful rinsing for about 10 minutes in order to properly remove the decalcification agent. Combining the protocols is not recommended, with heating and steering improving decalcification, and should always be considered. ${ }^{77}$ Even if protein degradation is quite different from the degradation of nucleic acids, current international pathology practice protocols require that the used protocols for tissue processing take into consideration DNA and/or RNA degradation. Thus, in order to also achieve a good tissue quality for molecular testing, the decalcification time is between 16 and 24 hours and the used substance is $14 \%$ ethylenediaminetetraacetic acid. Shortening this time is only acceptable for morphology assessment. In case the laboratory also requires molecular, cytogenetic, or flow cytometry assays, a longer time is required, as shown in Figure 3A-D.

\section{Conclusion}

Molecular diagnostics have become a reality. In the coming years, they will account for an increasingly significant fraction of the activity of pathology laboratories. In response to the new requirements, more and more laboratories will have to adapt their activities and implement, control, and standardize the procedures associated with the preanalytical phase. Each laboratory should create a dedicated unit, with specific equipment and specialist staff. The stages mentioned in the present article indicate that the pathologist is central in the processes required for molecular testing. The physicians working in pathology laboratories therefore will have to quickly familiarize themselves with the principles and techniques of molecular biology, thus acquiring dual competences, as morphological and also molecular pathologists.

\section{Acknowledgments}

Ravnit Grewal and Ciprian Tomuleasa contributed equally to the current paper and are considered senior authors. Sergiu Susman received funding from a PN-III-P2-2.1BG-2016-0117 grant awarded by the Romanian Government, as well as an internal grant (code 4944/4/08.03/2016) of the Iuliu Hatieganu University of Medicine and Pharmacy, Cluj Napoca. Ioana Berindan-Neagoe and Sergiu Susman were financed by the POSCCE 709/2010 grant with title: "Clini-

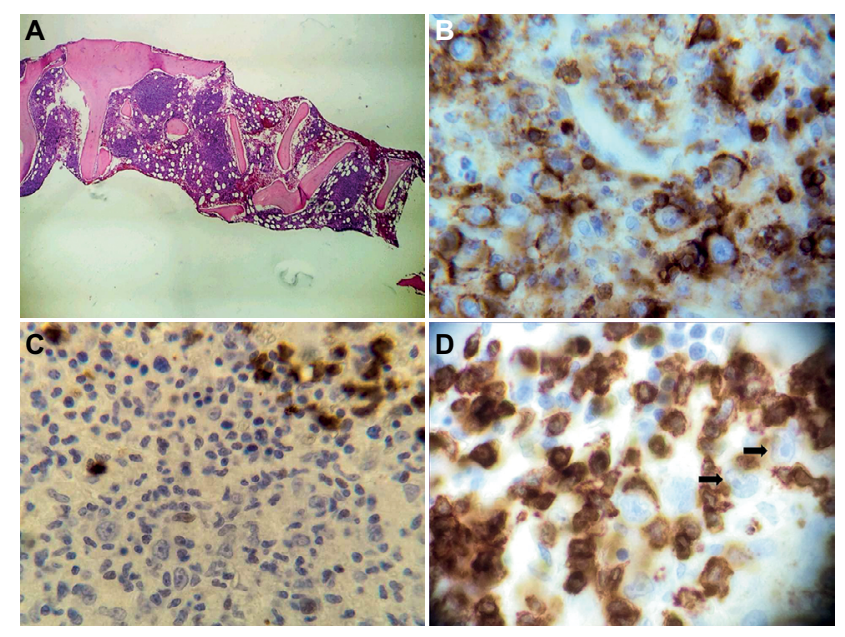

Figure 3 Pathology diagnosis in hematological malignancies.

Notes: (A) Bone marrow biopsy of a T-cell-rich/diffuse large B-cell lymphoma. (B) CD45 cells in a bone marrow biopsy of a T-cell-rich/diffuse large B-cell lymphoma. (C) CDI5 cells in a bone marrow biopsy of a T-cell-rich/diffuse large B-cell lymphoma. (D) CD3 negative staining in the large B cells but positive in the small T cells in a bone marrow biopsy of a T-cell-rich/diffuse large B-cell lymphoma (the black arrows show positive CD3+ cells). 
cal and economical impact of proteome and transcriptome molecular profiling in neoadjuvant therapy of triple negative breast cancer (BREASTIMPACT)". Ciprian Tomuleasa received funding from the Romanian Research Ministry, contracts PN-II-RU-TE-2014-4-1783 (awarded to Young Research Teams) and CNFIS-FDI-2017-1350 (awarded to Institutional Development Funds), as well as from an international collaboration grant between Romania and the People's Republic of China, contract 57 BM/2016.

\section{Disclosure}

The authors report no conflicts of interest in this work.

\section{References}

1. Kiernan U. Biomarker rediscovery in diagnostics. Expert Opin Med Diagn. 2008;2(12):1391-1400.

2. Patterson S, DuBose R. The role of biomarkers in the future of drug development. Expert Opin Drug Discov. 2006;1(3):199-204.

3. Lee JW, Figeys D, Vasilescu J. Biomarker assay translation from discovery to clinical studies in cancer drug development: quantification of emerging protein biomarkers. Adv Cancer Res. 2007;96:269-298.

4. Stopeck A, Brown-Glaberman U, Wong $\mathrm{H}$, et al. The role of targeted therapy and biomarkers in breast cancer treatment. Clin Exp Metastasis. 2012;29(7):807-819.

5. Kelley RK, Van Bebber SL, Phillips KA, Venook AP. Personalized medicine and oncology practice guidelines: a case study of contemporary biomarkers in colorectal cancer. J Natl Compr Canc Netw. 2011;9(1):13-25.

6. Corless CL, Barnett CM, Heinrich MC. Gastrointestinal stromal tumours: origin and molecular oncology. Nat Rev Cancer. 2011;1(12):865-878

7. Beelen K, Zwart W, Linn SC. Can predictive biomarkers in breast cancer guide adjuvant endocrine therapy? Nat Rev Clin Oncol. 2012;9(9):529-541.

8. Maes E, Broeckx V, Mertens I, et al. Analysis of the formalin-fixed paraffin-embedded tissue proteome: pitfalls, challenges, and future prospectives. Amino Acids. 2013;45(2):205-218.

9. Lippi G, Becan-McBride K, Behúlová D, et al. Preanalytical quality improvement: in quality we trust. Clin Chem Lab Med. 2013;51(1):229-241.

10. Ceriotti F, Cappelletti P, Caputo M, et al. A risk-analysis approach to the evaluation of analytical quality. Clin Chem Lab Med. 2011;50:67-71.

11. Dimenstein IB. Grossing biopsies: an introduction to general principles and techniques. Ann Diagn Pathol. 2009;13(2):106-113.

12. Novis DA. Detecting and preventing the occurrence of errors in the practices of laboratory medicine and anatomic pathology: 15 years' experience with the College of American Pathologists' Q-PROBES and Q-TRACKS programs. Clin Lab Med. 2004;24(4):965-978.

13. van Krieken J, Normanno N, Blackhall F, et al. Guideline on the requirements of external quality assessment programs in molecular pathology. Virchows Archiv. 2012;462(1):27-37.

14. Wolff AC, Hammond ME, Schwartz JN. American Society of Clinical Oncology/College of American Pathologists guideline recommendations for human epidermal growth factor receptor 2 testing in breast cancer. Arch Pathol Lab Med. 2007;131(1):18-43.

15. van Maldegem F, de Wit M, Morsink F, Musler A, Weegenaar J, van Noesel C. Effects of processing delay, formalin fixation, and immunohistochemistry on RNA recovery from formalin-fixed paraffin-embedded tissue sections. Diagn Mol Pathol. 2008;17:51-58.

16. Yildiz-Aktas IZ, Dabbs DJ, Bhargava R. The effect of cold ischemic time on the immunohistochemical evaluation of estrogen receptor, progesterone receptor, and HER 2 expression in invasive breast carcinoma Mod Pathol. 2012;25(8):1098-1105.
17. Buesa RJ, Peshkov MV. How much formalin is enough to fix tissues? Ann Diagn Pathol. 2012;16(3):202-209.

18. Berod A, Hartman BK, Pujol JF. Importance of fixation in immunohistochemistry: use of formaldehyde solutions at variable $\mathrm{pH}$ for the localization of tyrosine hydroxylase. $J$ Histochem Cytochem. 1981;29(7):844-850.

19. Zou N, Liang Q, He H, et al. Ultrasound-facilitated formalin fixation of biological specimens. Biotech Histochem. 2010;86(6):413-420.

20. Fox CH, Johnson FB, Whiting J, Roller PP. Formaldehyde fixation. $J$ Histochem Cytochem. 1985;33(8):845-853.

21. Khoury T, Sait S, Hwang H, et al. Delay to formalin fixation effect on breast biomarkers. Mod Pathol. 2009;22(11):1457-1467.

22. Goldstein NS, Ferkowicz M, Odish E, Mani A, Hastah F. Minimum formalin fixation time for consistent estrogen receptor immunohistochemical staining of invasive breast carcinoma. Am J Clin Pathol. 2003;120(1):86-92.

23. Tong LC, Nelson N, Tsourigiannis J, Mulligan AM. The effect of prolonged fixation on the immunohistochemical evaluation of estrogen receptor, progesterone receptor, and HER2 expression in invasive breast cancer: a prospective study. Am J Surg Pathol. 2011;35(4): $545-552$.

24. Hammond ME, Hayes DF, Dowsett M. American Society of Clinical Oncology/College of American Pathologists guideline recommendations for immunohistochemical testing of estrogen and progesterone receptors in breast cancer. Arch Pathol Lab Med. 2010;134(6):907-922.

25. Wolff AC, Hammond ME, Schwartz JN. American Society of Clinical Oncology/College of American Pathologists guideline recommendations for human epidermal growth factor receptor 2 testing in breast cancer. J Clin Oncol. 2007;25(1):118-145.

26. Espina V, Edmiston KH, Heiby M, et al. A portrait of tissue phosphoprotein stability in the clinical tissue procurement process. Mol Cell Proteomics. 2008;7(10):1998-2018.

27. Svensson M, Skold K, Nilsson A, et al. Neuropeptidomics: MS applied to the discovery of novel peptides from the brain. Anal Chem. 2007;79(1): $15-16$.

28. Juhl H. Preanalytical aspects: a neglected issue. Scand J Clin Lab Invest Suppl. 2010;70(suppl 242):63-65.

29. Morente M, Mager R, Alonso S, et al. TuBaFrost 2: standardising tissue collection and quality control procedures for a European virtual frozen tissue bank network. Eur J Cancer. 2006;42(16):2684-2691.

30. Ericsson C, Franzén B, Nistér M. Frozen tissue biobanks. Tissue handling, cryopreservation, extraction, and use for proteomic analysis. Acta Oncol. 2006;45(6):643-661.

31. Ahram M, Flaig MJ, Gillespie JW, et al. Evaluation of ethanol-fixed, paraffin-embedded tissues for proteomic applications. Proteomics. 2003;3(4):413-421.

32. Hood BL, Conrads TP, Veenstra TD. Mass spectrometric analysis of formalin-fixed paraffin-embedded tissue: unlocking the proteome within. Proteomics. 2006;6(14):4106-4114.

33. Shi S, Liu C, Balgley BM, Lee C, Taylor CR. Protein extraction from formalin-fixed, paraffin-embedded tissue sections: quality evaluation by mass spectrometry. J Histochem Cytochem. 2006;54(6):739-743.

34. Sprung R, Brock J, Tanksley J, et al. Equivalence of protein inventories obtained from formalin-fixed paraffin-embedded and frozen tissue in multidimensional liquid chromatography-tandem mass spectrometry shotgun proteomic analysis. Mol Cell Proteomics. 2009;8(8):1988-1998.

35. Stanta G, Mucelli SP, Petrera F, Bonin S, Bussolati G. A novel fixative improves opportunities of nucleic acids and proteomic analysis in human archive's tissues. Diagn Mol Pathol. 2006;15(2):115-123.

36. Mange A, Chaurand P, Perrochia H, Roger P, Caprioli RM, Solassol J. Liquid chromatography-tandem and MALDI imaging mass spectrometry analyses of RCL2/CS100-fixed, paraffin embedded tissues: proteomics evaluation of an alternate fixative for biomarker discovery J Proteome Res. 2009;8(12):5619-5628.

37. Hood BL, Darfler MM, Guiel TG, et al. Proteomic analysis of formalin-fixed prostate cancer tissue. Mol Cell Proteomics. 2005;4(11) 1741-1753. 
38. Nirmalan NJ, Harnden P, Selby PJ, Banks RE. Mining the archival formalin-fixed paraffin-embedded tissue proteome: opportunities and challenges. Mol Biosyst. 2008;4:712-720.

39. Olivieri E, Herbert B, Righetti PG. The effect of protease inhibitors on the two-dimensional electrophoresis pattern of red blood cell membranes. Electrophoresis. 2001;22(3):560-565.

40. Svensson M, Boren M, Sköld K, et al. Heat stabilization of the tissue proteome: a new technology for improved proteomics. J Proteome Res. 2009;8(2):974-981.

41. Wolff C, Schott C, Porschewski P, Reischauer B, Becker K. Successful protein extraction from over-fixed and long-term stored formalin-fixed tissues. PLoS One. 2011;6(1):e16353.

42. Nishimura T, Nomura M, Tojo H, et al. Proteomic analysis of lasermicrodissected paraffin-embedded tissues: (2) MRM assay for stage-related proteins upon non-metastatic lung adenocarcinoma. J Proteomics. 2010;73(6):1100-1110.

43. Chung J, Lee S, Kris Y, Braunschweig T, Traicoff J, Hewitt S. A wellbased reverse-phase protein array applicable to extracts from formalinfixed paraffin-embedded tissue. Proteomics. 2008;2(10-11):1539-1547.

44. Chung JY, Braunschweig T, Williams R, et al. Factors in tissue handling and processing that impact RNA obtained from formalin-fixed, paraffinembedded tissue. J Histochem Cytochem. 2008;56(11):1033-1042.

45. Hatzis C, Sun H, Yao H, et al. Effects of tissue handling on RNA integrity and microarray measurements from resected breast cancers. J Natl Cancer Inst. 2011;103(24):1871-1883.

46. Florell S, Coffin C, Holden J, et al. Preservation of RNA for functional genomic studies: a multidisciplinary tumor bank protocol. Mod Pathol. 2001;14(2):116-128.

47. Bao WG, Zhang X, Zhang JG, et al. Biobanking of fresh-frozen human colon tissues: impact of tissue ex-vivo ischemia times and storage periods on RNA quality. Ann Surg Oncol. 2012;20(5):1737-1744.

48. Micke P, Ohshima M, Tahmasebpoor S, et al. Biobanking of fresh frozen tissue: RNA is stable in nonfixed surgical specimens. Lab Invest. 2006;86(2):202-211.

49. Friede L, Grossman R, Hunt RM, Stern S. National Biospecimens Network Blueprint. Durham, NC: Costella Group Inc; 2003.

50. Freidin MB, Bhudia N, Lim E, Nicholson AG, Cookson WO, Moffatt MF. Impact of collection and storage of lung tumor tissue on whole genome expression profiling. J Mol Diagn. 2012;14(2):140-148.

51. Cronin M, Pho M, Dutta D, et al. Measurement of gene expression in archival paraffin-embedded tissues: development and performance of a 92-gene reverse transcriptase-polymerase chain reaction assay. $\mathrm{Am} \mathrm{J}$ Pathol. 2004;164(1):35-42.

52. Dotti I, Bonin S, Basili G, et al. Effects of formalin, methacarn, and fineFIX fixatives on RNA preservation. Diagn Mol Pathol. 2010;19(2): $112-122$.

53. Bussolati G, Annaratone L, Medico E, D’Armento G, Sapino A. Formalin fixation at low temperature better preserves nucleic acid integrity. PLoS One. 2011;6(6):e21043.

54. Srinivasan M, Sedmak D, Jewell S. Effect of fixatives and tissue processing on the content and integrity of nucleic acids. Am J Pathol. 2002;161(6):1961-1971.

55. Scicchitano M, Dalmas D, Bertiaux M, et al. Preliminary comparison of quantity, quality, and microarray performance of RNA extracted from formalin-fixed, paraffin-embedded, and unfixed frozen tissue samples. J Histochem Cytochem. 2006;54(11):1229-1237.

56. Chowdary D, Lathrop J, Skelton J, et al. Prognostic gene expression signatures can be measured in tissues collected in RNAlater preservative. J Mol Diagn. 2006;8(1):31-39.

57. Hoffman EP. Guidelines: expression profiling-best practices for data generation and interpretation in clinical trials. Nat Rev Genet. 2004;5(3):229-237.
58. Volinia S, Calin GA, Liu CG, et al. A microRNA expression signature of human solid tumors defines cancer gene targets. Proc Natl Acad Sci US A. 2006;103(7):2257-2261.

59. Turchinovich A, Weiz L, Langheinz A, Burwinkel B. Characterization of extracellular circulating microRNA. Nucleic Acids Res. 2011;39(16): 7223-7233.

60. Bovell L, Shanmugam C, Katkoori VR, et al. miRNAs are stable in colorectal cancer archival tissue blocks. Front Biosci. 2012;E4(1):1937.

61. Schuster C, Budczies J, Faber C, Kirchner T, Hlubek F. MicroRNA expression profiling of specific cells in complex archival tissue stained by immunohistochemistry. Lab Invest. 2011;91(1):157-165.

62. Jewell S, Srinivasan M, McCart L, et al. Analysis of the molecular quality of human tissues. Am J Clin Pathol. 2002;118(5):733-741.

63. Petras ML, Lefferts JA, Ward BP, Suriawinata AA, Tsongalis GJ. KRAS detection in colonic tumors by DNA extraction from FTA paper: the molecular touch-prep. Diagn Mol Pathol. 2011;20(4):189-193.

64. Ferrer I, Armstrong J, Capellari S, et al. Effects of formalin fixation, paraffin embedding, and time of storage on DNA preservation in brain tissue: a BrainNet Europe Study. Brain Pathol. 2007;17(3): 297-303.

65. Duval K, Aubin R, Elliott J, et al. Optimized manual and automated recovery of amplifiable DNA from tissues preserved in buffered formalin and alcohol-based fixative. Forensic Sci Int. 2010;4(2):80-88.

66. Hennig G, Gehrmann M, Stropp U, et al. Automated extraction of DNA and RNA from a single formalin-fixed paraffin-embedded tissue section for analysis of both single-nucleotide polymorphisms and mRNA expression. Clin Chem. 2010;56(12):1845-1853.

67. Sam SS, Lebel KA, Bissaillon CL, Tafe LJ, Tsongalis GJ, Lefferts JA. Automation of genomic DNA isolation from formalin-fixed, paraffinembedded tissues. Pathol Res Pract. 2012;208(12):705-707.

68. Williams C, Pontén F, Moberg C, et al. A high frequency of sequence alterations is due to formalin fixation of archival specimens. Am J Pathol. 1999;155(5):1467-1471.

69. Kerick M, Isau M, Timmermann B, et al. Targeted high throughput sequencing in clinical cancer settings: formaldehyde fixed-paraffin embedded (FFPE) tumor tissues, input amount and tumor heterogeneity. BMC Med Genomics. 2011;4:68.

70. Wagle N, Berger MF, Davis MJ, et al. High-throughput detection of actionable genomic alterations in clinical tumor samples by targeted, massively parallel sequencing. Cancer Discov. 2012;2(1):82-93.

71. Nassiri M, Gugic D, Olczyk J, Ramos S, Vincek V. Preservation of skin DNA for oligonucleotide array CGH studies: a feasibility study. Arch Dermatol Res. 2007;299(7):353-357.

72. Krijgsman O, Israeli D, Haan JC, et al. CGH arrays compared for DNA isolated from formalin-fixed, paraffin-embedded material. Genes Chromosomes Cancer. 2012;51(4):344-352.

73. Ionel A, Lucaciu O, Tăbăran F, et al. Histopathological and clinical expression of periodontal disease related to the systemic inflammatory response. Histol Histopathol. 2017;32(4):379-384.

74. Ciobanu L, Tantau M, Valean S, et al. Rifaximin modulates 5-fluorouracil-induced gastrointestinal mucositis in rats. Eur Rev Med Pharmacol Sci. 2016;20(23):4993-5001.

75. Lucan C, Pop LA, Florian A, et al. HLA genotyping using next generation sequencing. Rom J Intern Med. 2016;54(2):98-104.

76. Torlakovic EE, Brynes RK, Hyjek E, et al. ICSH guidelines for the standardization of bone marrow immunohistochemistry. Int $J$ Lab Hematol. 2015;37(4):431-449.

77. Dimenstein IB. Bone grossing techniques: helpful hints and procedures. Ann Diagn Pathol. 2008;12(3):191-198. 
Cancer Management and Research

\section{Publish your work in this journal}

Cancer Management and Research is an international, peer-reviewed open access journal focusing on cancer research and the optimal use of preventative and integrated treatment interventions to achieve improved outcomes, enhanced survival and quality of life for the cancer patient.

The manuscript management system is completely online and includes

Submit your manuscript here: https://www.dovepress.com/cancer-management-and-research-journal

a very quick and fair peer-review system, which is all easy to use. Visit $\mathrm{http}: / / \mathrm{www}$.dovepress.com/testimonials.php to read real quotes from published authors. 